\title{
ANALISIS EFISIENSI HASIL PENCACAHAN TERHADAP TIPE PENCACAH DAN MATERIAL SAMPAH
}

\author{
Adhe Anggry ${ }^{1}$, Subkhan ${ }^{2}$ \\ ${ }^{1,2}$ Jurusan Teknik Mesin - Politeknik Manufaktur Negeri Bangka Belitung \\ Kawasan Industri Airkantung Sungailiat, \\ Telp.0717-93586, Fax.0717-93585, adhe.anggry@yahoo.com
}

\begin{abstract}
Waste is one of the many social problems faced by the community. To solve the problem of waste required a technology to process waste itself. Several studies have been done, one of which is design and construction thrasher machine. There are several studies on the design and construction thrasher machine. However, the analysis was conducted on one type of thrasher machine with a particular waste material. This study aims to obtain the results of the efficiency analysis of the thrasher machine results on the type of thrasher machine and waste material. The method used is experimental method. The type of thrasher machine and waste material used as a free variable. The percentage of the chopping result is chosen as a variable depending on the speed of rotation and thrasher time as the companion variable. The results of this study based on the results of experiments, both qualitatively and quantitatively shows that plastic bottle trash has a suit with shear type, grass litter has a match with the type of swing and trash has a match with the type of crusher.
\end{abstract}

Keywords: thrasher machine, waste, crusher type, shear type, swing type

\begin{abstract}
Abstrak
Sampah merupakan salah satu dari sekian banyak masalah sosial yang dihadapi masyarakat. Untuk mengatasi masalah sampah, diperlukan sebuah teknologi mengolah sampah itu sendiri. Beberapa kajian telah dilakukan, salah satunya adalah rancang bangun mesin pencacah sampah. Terdapat beberapa penelitian tentang rancang bangun mesin pencacah sampah. Namun demikian, analisis dilakukan pada satu tipe pencacah dengan material sampah tertentu. Penelitian ini bertujuan untuk mendapatkan hasil analisis efisiensi hasil pencacah terhadap tipe pencacah dan material sampah. Metode yang digunakan adalah metode eksperimen. Tipe pencacah dan material sampah digunakan sebagai peubah bebas. Prosentase hasil cacahan dipilih sebagai peubah tergantung dengan kecepatan putar dan waktu pencacahan sebagai peubah penyerta. Berdasarkan hasil eksperimen baik secara kualitatif maupun kuantitatif menunjukkan bahwa sampah botol plastik memiliki kecocokan dengan tipe shear, sampah rumput memiliki kecocokan dengan tipe swing dan sampah ranting memiliki kecocokan dengan tipe crusher.
\end{abstract}

Kata kunci: mesin pencacah, sampah, tipe crusher, tipe shear, tipe swing

\section{[1]. PENDAhULUAN}

Sampah merupakan salah satu dari sekian banyak masalah sosial yang dihadapi masyarakat. Untuk mengatasi masalah sampah, diperlukan sebuah teknologi mengolah sampah itu sendiri. Salah satunya adalah mesin pencacah sampah. Studi tentang rancang bangun mesin pencacah untuk pengolahan sampah sudah banyak dilakukan, seperti pengembangan mesin pencacah sampah/limbah plastik dengan sistem crusher dan silinder pemotong tipe reel [1], mesin pencacah plastik yang dikembangkan memiliki 2 jenis mekanisme pencacah yaitu tipe crusher dan tipe shear dimana sampah plastik mengalami dua kali proses pencacahan untuk mendapatkan hasil yang diinginkan. Hasil pengujian kinerja mesin dengan $\varnothing$ lubang saringan $1,5 \mathrm{~cm}$, dengan keseragaman butiran $80 \%$. Rancang 
bangun mesin pencacah plastik sebagai bahan baku mesin pirolisis skala komunal [2], mesin pencacah plastik yang dikembangkan memiliki 1 jenis mekanisme pencacah yaitu tipe shear. Hasil pengujian kinerja mesin dengan $\varnothing$ lubang saringan $2 \mathrm{~cm}$ untuk botol minuman PET, mesin sudah berfungsi sesuai harapan. Desain dan uji kinerja mesin pencacah rumput gajah tipe reel [3], mesin pencacah plastik yang dikembangkan memiliki 1 jenis mekanisme pencacah yaitu tipe shear. Hasil pengujian kinerja mesin, panjang hasil pemotongan terhadap rumput gajah adalah $1-3 \mathrm{~cm}$. Pada penelitian-penelitian tersebut, tipe pencacah yang digunakan adalah tipe shear untuk material sampah plastik dan rumput.

Berdasarkan evaluasi dari penelitian-penelitian diatas, penelitian untuk pencocokan tipe pencacah sampah dengan material sampah perlu dilakukan. Penelitian ini tentang pencocokan tipe pencacah sampah dengan material sampah. Hasil analisis yang ingin dicapai adalah prosentase hasil pencacah terhadap tipe pencacah dan material sampah.

\section{[2]. METODE PENELITIAN}

\section{a. TAHAPAN PENELITIAN}

1 berikut ini:

Langkah-langkah yang dilakukan dalam penelitian ini disajikan dalam diagram alir pada Gambar

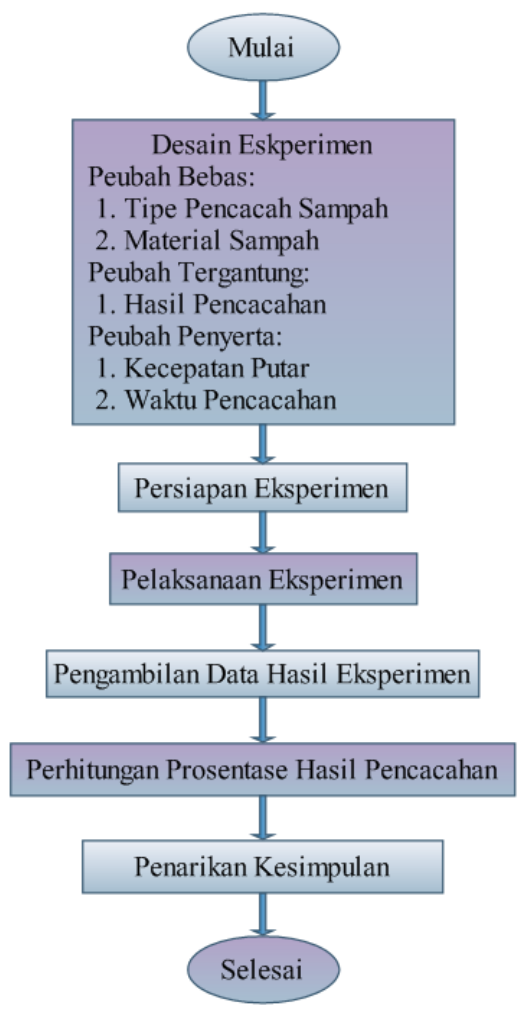

Gambar 1. Diagram Alir Tahapan Penelitian

\section{b. PENGUBAH YANG DIAMATI/DIUKUR}

Data-data yang digunakan pada penelitian ini merupakan data primer yang diperoleh dari hasil eksperimen. Peubah bebas yang diamati/diukur adalah prosentase hasil cacahan sesuai ukuran yang diinginkan. Tipe pencacah dan material sampah digunakan sebagai peubah bebas. Tipe pencacah terdiri dari tiga jenis cutting block yaitu tipe crusher, shear dan swing, material sampah yang dipilih adalah sampah botol plastik, rumput dan ranting, sedangkan kecepatan putar dan waktu pencacahan dipilih sebagai peubah penyerta. 


\section{c. BAHAN DAN PERALATAN}

Sebelum melakukan eksperimen dilakukan persiapan-persiapan terhadap mesin pencacah sampah, cutting block, material sampah, penyaring, peralatan ukur, dan peralatan bantu yang akan digunakan. Mesin pencacah sampah dan cutting block yang digunakan ditunjukkan pada Gambar 2. Material sampah yang digunakan ditunjukkan pada Gambar 3.
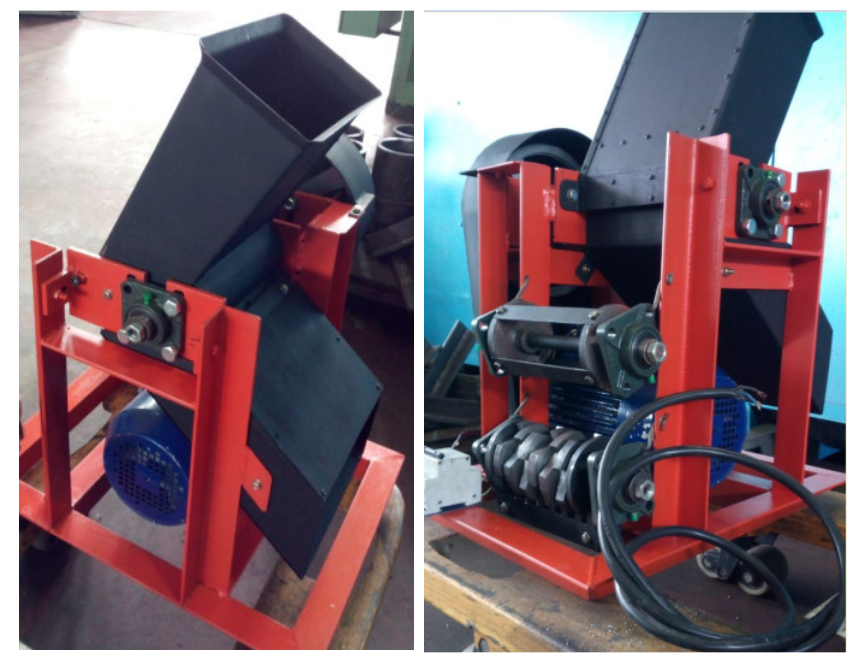

Gambar 2. Mesin Pencacah Sampah dan Cutting Block
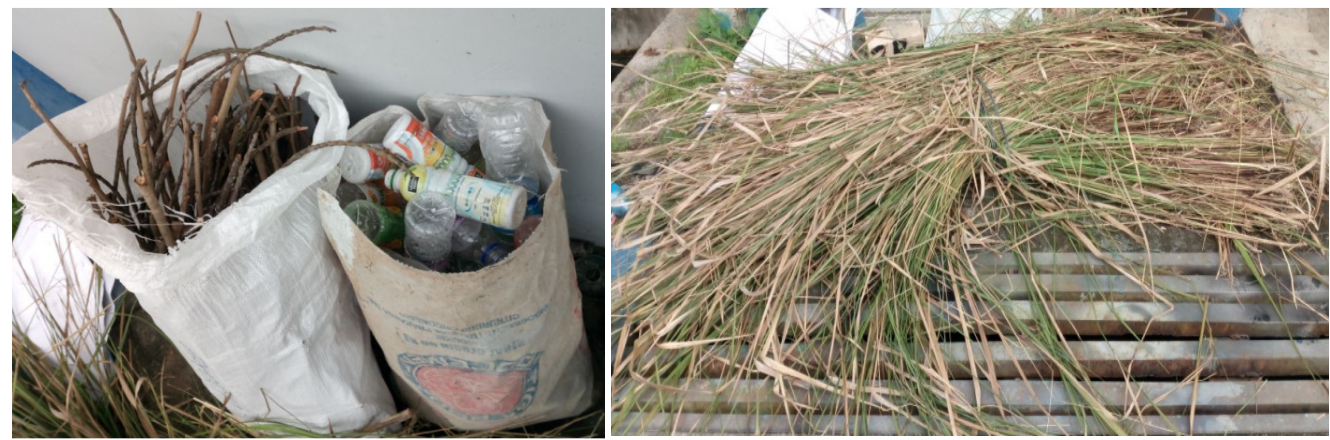

Gambar 3. Material Sampah

\section{d. MODEL YANG DIGUNAKAN}

Model yang digunakan dalam penelitian ini adalah sebagai berikut:

$$
\% \text { hasil }=\frac{\text { volume output }}{\text { volume input }} \times 100 \%
$$

Volume output yang dimaksud diatas adalah volume hasil cacahan sesuai ukuran yang diinginkan. Volume hasil dipengaruhi oleh kecepatan putar, torsi, sifat alat potong, dan karakteristik material input (jenis sampah).

\section{[3]. HASIL DAN PEMBAHASAN}

\section{a. DATA HASIL EKSPERIMEN}

Eksperimen dilakukan dengan mengkombinasikan tipe pencacah dan material sampah. Hasil eksperimen secara keseluruhan ditunjukkan pada Tabel 1. Data yang diambil pertama kali adalah hasil cacahan menggunakan cutting block tipe shear pada kecepatan putar $300 \mathrm{rpm}$. Sampah botol plastik dengan waktu pencacahan 40 detik dan volume input $0,2 \mathrm{~kg}$, botol plastik tidak dapat tercacah tetapi 
hanya terkoyak. Volume output untuk sampah rumput dengan waktu pencacahan 180 detik dan volume input $0,5 \mathrm{~kg}$ diperoleh tiga ukuran yang berbeda. Hasil pencacahan dengan ukuran $100 \mathrm{~mm}$ seberat 0,2 $\mathrm{kg}$, ukuran $50 \mathrm{~mm}$ seberat $0,2 \mathrm{~kg}$ dan ukuran $10 \mathrm{~mm}$ seberat 0,1 kg. Volume output untuk sampah ranting dengan waktu pencacahan 60 detik dan volume input $0,5 \mathrm{~kg}$ diperoleh hasil pencacahan dengan ukuran $30 \mathrm{~mm}$ seberat $0,1 \mathrm{~kg}$, ukuran $20 \mathrm{~mm}$ seberat $0,1 \mathrm{~kg}$ dan sisanya berukuran dibawah $20 \mathrm{~mm}$.

Data yang diambil berikutnya adalah hasil cacahan menggunakan cutting block tipe crusher pada kecepatan putar 300 rpm. Sampah botol plastik dengan waktu pencacahan 30 detik dan volume input $0,5 \mathrm{~kg}$, botol plastik tidak dapat tercacah tetapi hanya penyok. Volume output untuk sampah rumput dengan waktu pencacahan 31 detik dan volume input 0,5 $\mathrm{kg}$ diperoleh hasil pencacahan dengan ukuran $60 \mathrm{~mm}$ seberat $0,1 \mathrm{~kg}$ dan sisanya tertinggal di cutting block. Volume output untuk sampah ranting dengan waktu pencacahan 130 detik dan volume input $1 \mathrm{~kg}$ diperoleh hasil pencacahan dengan ukuran $10 \mathrm{~mm}$ seberat $0,3 \mathrm{~kg}$ dan sisanya tidak keluar.

Data yang diambil berikutnya adalah hasil cacahan menggunakan cutting block tipe swing pada kecepatan putar $300 \mathrm{rpm}$. Sampah botol plastik dengan waktu pencacahan 20 detik dan volume input $0,5 \mathrm{~kg}$, botol plastik tidak dapat tercacah tetapi hanya penyok. Volume output untuk sampah rumput dengan waktu pencacahan 10 detik dan volume input $0,5 \mathrm{~kg}$ diperoleh hasil pencacahan dengan ukuran $100 \mathrm{~mm}$ seberat $0,3 \mathrm{~kg}$ dan sisanya tidak keluar. Volume output untuk sampah ranting dengan waktu pencacahan 20 detik dan volume input 0,5 kg tidak dapat tercacah.

Tabel 1. Data Hasil Eksperimen

\begin{tabular}{|c|c|c|c|}
\hline \multirow{2}{*}{ Parameter Ukur } & \multicolumn{3}{|c|}{ Material Sampah } \\
\hline & Botol Plastik & Rumput & Ranting \\
\hline & \multicolumn{3}{|c|}{ Tipe Shear } \\
\hline Putaran (rpm) & \multicolumn{3}{|c|}{300} \\
\hline Waktu (detik) & 40 & 180 & 60 \\
\hline \multirow[t]{2}{*}{ Input (kg) } & 0,2 & 0,5 & 0,5 \\
\hline & 0 & $100 / 0,2$ & $30 / 0,1$ \\
\hline \multirow[t]{3}{*}{ Output (mm/kg) } & & $50 / 0,2$ & $20 / 0,1$ \\
\hline & & $10 / 0,1$ & \\
\hline & \multicolumn{3}{|c|}{ Tipe Crusher } \\
\hline Putaran (rpm) & \multicolumn{3}{|c|}{300} \\
\hline Waktu (detik) & 30 & 31 & 130 \\
\hline Input (kg) & 0,5 & 0,5 & 1 \\
\hline \multirow[t]{2}{*}{ Output (mm/kg) } & 0 & $60 / 0,1$ & $10 / 0,3$ \\
\hline & \multicolumn{3}{|c|}{ Tipe Swing } \\
\hline Putaran (rpm) & \multicolumn{3}{|c|}{300} \\
\hline Waktu (detik) & 20 & 10 & 20 \\
\hline Input (kg) & 0,5 & 0,5 & 0,5 \\
\hline Output (mm/kg) & 0 & $100 / 0,3$ & 0 \\
\hline
\end{tabular}

\section{b. ANALISIS DATA}

Prosentase hasil pencacahan dihitung menggunakan persamaan 1. Contoh perhitungan prosentase hasil pencacahan menggunakan cutting block tipe shear dan material sampah rumput dengan ukuran $100 \mathrm{~mm}$ adalah sebagai berikut:

$$
\% \text { hasil }=\frac{0,2}{0,5} \times 100 \%=40 \%
$$

Sesuai dengan perhitungan yang telah dilakukan, prosentase hasil pencacahan yang diperoleh untuk masing-masing tipe pencacah dan material sampah ditunjukkan pada Tabel 2. 
Tabel 2. Prosentase Hasil Pencacahan

\begin{tabular}{lccc}
\hline \multirow{2}{*}{ Peubah } & Tipe Shear & Tipe Crusher & Tipe Swing \\
\cline { 2 - 4 } & & $\mathrm{mm} / \%$ & \\
\hline \hline Sampah Botol Plastik & $0 / 0$ & $0 / 0$ & $0 / 0$ \\
\hline \multirow{3}{*}{ Sampah Rumput } & $100 / 40$ & $60 / 20$ & $100 / 60$ \\
\cline { 2 - 4 } & $50 / 40$ & $0 / 0$ \\
\cline { 2 - 4 } & $10 / 20$ & $10 / 30$ \\
\hline Sampah Ranting & $30 / 20$ & \\
\cline { 2 - 4 } & $20 / 20$ & & \\
\hline
\end{tabular}

Sumber: Hasil Perhitungan

Berdasarkan data hasil pencacahan, sampah botol plastik tidak tercacah untuk ketiga tipe pencacah. Mata potong tipe shear dan swing tidak cukup tajam untuk memisahkan ikatan plastik. Konstruksi tipe crusher dibuat tidak sesuai desain yang tidak memberi sudut bebas yang memadai untuk mencacah plastik. Hasil pencacahan untuk sampah ranting, untuk pencacah tipe shear ranting tidak keluar karena desain ruang antar pisau tidak cukup lebar untuk memberi kesempatan ranting untuk masuk. Pada pencacah tipe crusher ranting tidak keluar, hal ini disebabkan pemotongan terjadi pada arah melintang ranting. Tinjauan desain yang dapat dilakukan adalah menambah pengarah untuk posisi di arah melintang atau memberi sudut bebas yang cukup pada mata potong dan memberi ruang yang cukup untuk ranting masuk. Pada proses pencacahan dengan menurunkan kecepatan putar dikisaran $100 \mathrm{rpm}$. Mata potong pencacah tipe swing tidak cukup tajam (sudut baji terlalu besar/ sudut bebas terlalu kecil) sehingga ranting tidak tercacah. Hasil pencacahan untuk sampah rumput, pencacah tipe shear dapat mencacah rumput dengan baik. Mata potong pencacah tipe crusher tidak cukup tajam untuk mencacah rumput sehingga rumput tidak tercacah. Pada pencacah tipe swing, rumput tidak keluar, hal ini karena tidak ada yang melawan gaya tarik swing untuk memungkinkan terjadinya pemotongan. Tinjauan desain yang dapat dilakukan adalah desain dilengkapi dengan mekanisme penahan untuk melawan gaya tarik swing.

\section{[4]. SIMPULAN}

Analisis efisiensi hasil pencacahan terhadap tipe pencacah dan material sampah berdasarkan hasil eksperimen baik secara kualitatif maupun kuantitatif dapat ditarik kesimpulan bahwa sampah botol plastik memiliki tingkat kecocokan lebih baik dengan tipe shear walaupun belum dapat tercacah tetapi botol plastik sudah dapat tergoyak, sampah rumput untuk ukuran cacahan $100 \mathrm{~mm}$ memiliki tingkat kecocokan lebih baik dengan tipe swing dengan prosentase hasil pencacahan $60 \%$ dan sampah ranting untuk ukuran cacahan $10 \mathrm{~mm}$ memiliki tingkat kecocokan lebih baik dengan tipe crusher dengan prosentase hasil pencacahan $30 \%$.

\section{DAFTAR PUSTAKA}

[1]. Ichlas Nur, "Pengembangan Mesin Pencacah Sampah/Limbah Plastik dengan Sistem Crusher dan Silinder Pemotong Tipe Reel", Prosiding Seminar Nasional Sains dan Teknologi (SEMNATEK), Fakultas Teknik Universitas Muhammadiyah Jakarta, Jakarta, pp. 1-7, 2014.

[2]. Mochamad Syamsiro, "Rancang Bangun Mesin Pencacah Plastik Sebagai Bahan Baku Mesin Pirolisis Skala Komunal", Jurnal Mekanika dan Sistem Termal (JMST), Vol. 1, no.2, pp. 43-48, 2016.

[3]. Wahyu K. Sugandi, "Desain dan Uji Kinerja Mesin Pencacah Rumput Gajah Tipe Reel", Jurnal Teknotan, vol. 8, no.1, pp. 52-60, 2016. 